\title{
TRABALHO E SAÚDE NA INDÚSTRIA TÊXTIL DE AMIANTO
}

\author{
V ANDA D'ACRI
}

\begin{abstract}
Resumo: A morbidade e a mortalidade dos trabalhadores da indústria têxtil de amianto no Rio de Janeiro revelam o grande dano causado por esta matéria-prima, proibida em diversos países e utilizada em outros, como no Brasil, por interesse econômico e político. Quanto ao significado do trabalho, a proposta de uma vida cheia de sentido implica uma outra organização societária, em que o ato de trabalhar não seja de adoecimento e morte, mas sim uma ação saudável, um espaço de criação e liberdade para os trabalhadores.

Palavras-chave: saúde; amianto e significado do trabalho.
\end{abstract}

\begin{abstract}
The morbidity and mortality rates of workers at an asbestos plant in Rio de Janeiro reveal the great harm caused by this raw material, which is prohibited in many countries but used in others, such as Brazil, due to economic and political interests. The definition of a full life implies a reality in which the act of working does not lead to sickness and death. Ideally, working should be a healthy activity, and the workplace should provide a space for workers' creativity and freedom.

Key words: health; asbestos; the meaning of work.
\end{abstract}

$\mathrm{O}$ significado do trabalho e a saúde dos trabalhadores de uma indústria têxtil de amianto no Rio de Janeiro são os pontos centrais deste estudo. A relevância do tema saúde é decorrência da alta patogenicidade da matéria-prima amianto, também denominado asbesto, utilizada no processo produtivo. À importância da questão soma-se a inexistência de dados oficiais sobre diagnóstico dos trabalhadores deste ramo da indústria no Rio de Janeiro e o desconhecimento dos danos que atingem o ambiente e a população em geral. $\mathrm{O}$ antigo interesse em conhecer o significado que o trabalho tem para aqueles que trabalham, aliado ao atual desejo de conhecer a vivência dos trabalhadores na sua condição operária, levou a identificar que a subjetividade no trabalho é um dos fatores fundamentais na vida dos trabalhadores da fábrica em questão.

A pesquisa que forneceu os dados relativos à saúde e às condições sociais dos trabalhadores da indústria têxtil de amianto foi desenvolvida entre 1998 e início de 1999 e resultou em um relatório epidemiológico e social. O diagnóstico de asbestose e as condições de trabalho a que estavam expostos os trabalhadores, identificados no presente estudo, fazem emergir uma realidade de saúde até então desconhecida para as autoridades sanitárias do Rio de Janeiro.

O estudo epidemiológico e social deixa claro a lógica de gerenciamento utilizada pela empresa, em que a demissão já está prevista no próprio processo de admissão dos trabalhadores, como decorrência do adoecimento desse processo produtivo e utilização da matéria-prima amianto.

A comprovação desses fatos, através das inter-relações dos dados, revela um problema político e econômico, tanto nacional como internacional, uma vez que envolve o debate sobre o uso controlado ou extermínio da fibra de amianto e, consequientemente, a utilização de tecnologias alternativas. Tal discussão levou muitos países a banirem o amianto do seu processo produtivo, como também proibirem o uso dos produtos que contenham amianto.

O estudo do significado do trabalho e as condições de trabalho e saúde dos trabalhadores desta indústria deram uma dimensão humana do trabalho que não fazia parte da hipótese levantada na formulação da pesquisa. Ao procurar entender o processo de adoecimento e suas causas, na manipulação da matéria-prima amianto, procurou-se apreender como era vivida, experimentada e traduzida a forma objetiva e subjetiva do ato de trabalhar. 
$\mathrm{O}$ ato de trabalhar, que não era opcional, mas sim condição primeira de sobrevivência, exigia um aprofundamento dos sentimentos dos trabalhadores sobre suas vidas e seu trabalho, o que foi se revelando como um dado novo que contradizia a hipótese levantada de que o significado do trabalho, nestas condições tão penosas, só era possível como resultado da necessidade econômica.

A doença contraída pelos trabalhadores em decorrência do processo produtivo, como a asbestose que atingiu um grande número de pessoas e o sofrimento psíquico levaram os trabalhadores à indignação, o que resultou numa atitude concreta de reivindicação de seus direitos e organização, através da fundação da Associação Brasileira dos Expostos ao Amianto (Abrea-Rio), a exemplo de Osasco, que reúne um grande número de trabalhadores que estiveram expostos ao amianto. Contudo, esse quadro de morbidade e exploração capitalista deixa ainda antever o caráter ontológico do trabalho: a maioria dos trabalhadores vê sentido no seu trabalho, com o sentimento de construção e realização do seu atuar no mundo. Tal perspectiva levou à indagação de como é possível, num quadro tão negativo, existirem um sentido, um significado e uma valorização do trabalho. É na tentativa de responder esta questão que se desenvolve um dos aspectos dessa pesquisa.

No início da pesquisa não se esperava que o surgimento das questões relativas ao significado do trabalho levasse à perspectiva ontológica do trabalho, suscitada pelas falas dos trabalhadores, na expressão de sua subjetividade em relação à saúde comprometida por precárias condições de trabalho, ressaltando a importância do seu trabalho para além da sobrevivência, no dizer de Ricardo Antunes (1999).

Ao se lidar com a realidade do adoecimento dos trabalhadores, com a recusa do empresariado em reconhecer suas causas e com a omissão política e social das instâncias públicas responsáveis pelo setor econômico e aqueles voltados para a saúde da população, fica evidente o conseqüente privilegiamento do setor econômico em detrimento dos trabalhadores, revelando-se a importância dada ao capital em detrimento do trabalho.

A pesquisa partiu da demanda de uma trabalhadora ao serviço de atenção médica do Centro de Estudos em Saúde do Trabalhador e Ecologia Humana (Cesteh), em decorrência de sua saúde ter sido afetada por 14 anos de exposição a essa fibra mineral na indústria têxtil. O encaminhamento foi feito por uma médica da rede municipal de saúde, que levantou a hipótese diagnóstica da doença ocupacional relacionada à exposição ao amianto.
Diante do diagnóstico de asbestose, a equipe de pesquisadores solicitou a esta trabalhadora que entrasse em contato com outros operários que trabalharam na fábrica. Através de sua rede de relações, foram contatados diversos trabalhadores e encaminhados ao Cesteh.

A partir dessa consulta inicial, o Cesteh, da Escola Nacional de Saúde Pública, atendeu a 119 trabalhadores da referida fábrica, até setembro de 2001, que tinham sido demitidos em sua maioria. Destes, foram identificados 30 trabalhadores com o diagnóstico de asbestose, comprovado por exames clínicos, radiológicos e prova de função respiratória, além de tomografia computadorizada para melhores esclarecimentos, quando necessário.

As análises e interpretações desse estudo são um recorte desse universo de trabalhadores, envolvendo 41 funcionários da referida fábrica, sendo 23 mulheres (57\%) e 18 homens (43\%), durante 1998 e janeiro de 1999.

Dos 41 trabalhadores entrevistados, 15 têm o diagnóstico de asbestose (nove mulheres e seis homens) e 26 não o possuem. A concentração por tempo de serviço de sete trabalhadores com o diagnóstico de asbestose - entre $9 \mathrm{e}$ 15 anos de serviço - revela a intensa exposição a que estavam submetidos.

A média de permanência na atividade laborativa gira em torno de 15 anos. Este é o tempo em que os sintomas da doença começam a aparecer - cansaço, dificuldades respiratórias com conseqüente redução da produtividade -, a partir dos quais os trabalhadores são demitidos (Castro et al., 1999).

A fiação é o setor considerado pelos trabalhadores como um dos mais poluídos devido à excessiva poeira de amianto no ambiente. É o setor da produção que aloca o maior número de trabalhadores, o que mais adoece e é predominantemente feminino. Observa-se que entre os 15 trabalhadores com diagnóstico de asbestose, dez exerceram suas atividades na fiação, sendo sete mulheres e três homens; estes últimos exerceram suas atividades de trabalho também na calandra e gaxeta. Os outros trabalhadores eram duas tecelãs, dois trabalhadores do papelão hidráulico e um eletricista de máquinas.

Nestes setores produtivos, a distribuição por sexo segue a racionalidade da divisão sexual do trabalho nas empresas, em que os postos de trabalho femininos, como a fiação, exigem uma atividade repetitiva e intensa, com habilidade manual, além de força e atenção, enquanto nos masculinos, como o PH (papelão hidráulico), a insalubridade e o perigo são predominantes. 
A empresa não presta informações completas sobre os danos causados pelo amianto, não fornece nenhum diagnóstico aos trabalhadores e nega-se a reconhecer o nexo causal da asbestose relacionada à atividade na indústria, mesmo após a comprovação do diagnóstico feito pelo Cesteh.

De maio de 1999 a setembro de 2000, novos dados foram acrescentados aos resultados obtidos pela pesquisa. A ocorrência de óbitos dos trabalhadores tornou-se uma realidade nova e concreta. Foram registradas cinco mortes entre os trabalhadores atendidos pelo Cesteh, sendo quatro casos de asbestose e um de câncer de pulmão, segundo diagnóstico dos hospitais da rede pública de saúde.

O amianto ou asbesto é uma fibra mineral, composta por diversos minerais, como silicatos de magnésio, ferro, cálcio e sódio, e classifica-se em dois grupos: as serpentinas, ou crisotila, também denominadas de amianto branco, e os anfibólios, que compreendem uma grande variedade de tipos de fibras - a amosita (amianto marrom), a crocidolita (amianto azul), a antofilita, a actnolita e a tremolita (Castro; Lemle, 1995; Mendes, 2001).

Atualmente, a quase totalidade da produção mundial é de crisotila, pois os anfibólios, devido à sua comprovada nocividade à saúde humana, foram proibidos em quase todo mundo.

O valor comercial do amianto está relacionado às suas propriedades físicas: é incombustível, isolante de calor em temperaturas moderadas, tem alta resistência mecânica e baixa condutibilidade elétrica, alta resistência a substâncias químicas agressivas, capacidade de filtrar os microorganismos e outras substâncias nocivas, alta durabilidade e baixo custo para sua extração, pois são encontrados em rochas a céu aberto (Castro; Gomes, 1998).

Tais características tornam o amianto de grande utilização industrial e comercial. No Brasil, o amianto tem sido empregado em muitos produtos, principalmente na indústria de fibrocimento (caixas d'água, telhas de amianto, tubos de água e vasos), na indústria têxtil de amianto (tecidos em geral, para confecção de luvas industriais, roupas para bombeiros e gaxetas), na produção de papéis (papéis isolantes, papelão hidráulico, papelão industrial e filtros), na indústria automobilística (pastilhas e lonas de freios para automóveis, materiais de fricção, sapatas de trens, juntas de vedação), na produção de pisos vinílicos e outros produtos (Giannasi; Scavone; Mony, 1999; Castro et al., 2001).

As patologias causadas pelo amianto são: asbestose pulmonar (doença crônica que causa a fibrose no pulmão); câncer de pulmão e outros; mesoteliomas, que compreendem câncer de pleura e de peritônio (membranas que envolvem o pulmão e abdômen, respectivamente), e doenças pleurais benignas, como placas pleurais e limitação crônica do fluxo aéreo (Castro; Gomes, 1998).

Baseado na realidade concreta dos trabalhadores, organizou-se a Rede Mundial do Banimento do Amianto, composta por organizações dos trabalhadores, da sociedade civil e de pesquisadores de todo o mundo, no sentido de lutarem pelo banimento dessas fibras, reconhecimento dos direitos dos trabalhadores e esclarecimento da opinião pública sobre os males causados à saúde e ao meio ambiente. No Brasil, o limite para o asbesto crisotila é de 2,0 fibras por $\mathrm{cm}^{3}$ de ar.

\section{O SIGNIFICADO DO TRABALHO PARA OS OPERÁRIOS}

Esta análise tem como finalidade compreender o significado do trabalho para aqueles que trabalham; no caso específico, os trabalhadores de uma indústria têxtil de amianto no Rio de Janeiro.

Para o entendimento do sentido do trabalho, torna-se necessária uma abordagem sobre o trabalho, na tentativa de apreensão do seu caráter ontológico. Esta análise será feita através dos conceitos de trabalho, alienação, trabalho abstrato, trabalho concreto e reino da necessidade e liberdade, possibilitando uma reflexão que esclareça o significado do trabalho em sua fundamentação filosófica.

Algumas questões se impõem: a análise da relação entre o sentido econômico e o filosófico do trabalho; seu sentido ontológico; e a alienação do trabalho e sua superação.

Para Marx (1980), a análise do trabalho como atividade econômica é direcionada a um fim que, através do objeto de trabalho (matéria-prima) e dos meios de trabalho (seus instrumentos), cria valores de uso e de troca, por meio das mercadorias. $\mathrm{O}$ valor de qualquer mercadoria é determinado pela quantidade de trabalho materializado em seu valor de uso e pelo tempo de trabalho socialmente necessário à sua produção (Marx, 1980).

A reflexão sobre o sentido do trabalho só pode ser realizada a partir de uma discussão filosófica da fundamentação do conceito geral de trabalho, sua posição e sentido no âmbito da existência humana (Marcuse, 1998). Marx elaborou o conceito de trabalho a partir de Hegel, para o qual trata-se de um conceito central no sistema de análise da sociedade; $o$ autor apreendeu a natureza do trabalho; $o$ 
homem é resultado do seu trabalho, é o ato de auto-elaboração, de auto-objetivação do homem (Marcuse, 1998).

\section{O Conceito de Trabalho}

Para Marx (1980:202), o trabalho é a relação do homem com a natureza. "É um processo de que participam o homem e natureza, processo em que o ser humano com sua própria ação impulsiona, regula e controla seu intercâmbio material com a natureza".

A necessidade de idealizar em sua mente a forma que terá o seu trabalho - a concepção de sua intenção-resulta em ato criativo, através da definição de seus objetivos na materialidade dos objetos, que atende a suas necessidades e desejos.

Para Marx, o processo de trabalho é a atividade dirigida com o fim de criar valores de uso, cuja finalidade é o atendimento às necessidades humanas úteis e necessárias; é condição natural e eterna da vida humana, sendo comum a todas as formas de vida social (Marx, 1980).

Em Os manuscritos econômicos e filosóficos, Marx identifica a verdadeira dimensão que o trabalho assumiu para os homens, em sua maioria, na sociedade capitalista. Tomou a forma do trabalho alienado, constatando que o trabalho "não constitui a satisfação de uma necessidade, mas apenas um meio de satisfazer outras necessidades" (Marx, 1993:162). O trabalho tornou-se apenas um meio de sobrevivência, de manutenção da existência humana, e a não realização do reino da liberdade.

A alienação do trabalho se dá em dois aspectos: na relação do trabalhador com o produto do seu trabalho e também no próprio processo produtivo.

$\mathrm{Na}$ análise do trabalho alienado, Marx, a partir dos dois aspectos mencionados, refere-se também a um terceiro fator: a universalidade do homem, que é um ser genérico e, portanto, livre. Para o autor, o trabalho alienado transforma a vida genérica - vida universal - em vida individual.

"A vida produtiva, porém, é a vida genérica. É a vida criando vida. No tipo de atividade vital reside todo o caráter de uma espécie, o seu caráter genérico; e a atividade livre, consciente constitui o caráter genérico do homem" (Marx, 1993:163).

Marx afirma que a alienação do trabalhador em sua vida produtiva se reflete nas suas relações sociais com os outros homens e com a sociedade em geral. O conceito fundamental para a compreensão do homem em sua relação concreta de vida é a liberdade. O entendimento do signi- ficado do trabalho para os seres humanos e o conceito de alienação ligado ao próprio trabalho remetem ao conceito de liberdade. A análise de Marcuse (1969:100) sobre a fenomenologia do espírito de Hegel destaca que "a natureza do homem exige a liberdade e a liberdade é uma forma de razão, baseando este princípio na própria história do homem".

Em $A$ ideologia alemã , enfatizando a condição histórica dos homens, Marx e Engels (1999) afirmam que os homens devem estar em condições de viver para poder fazer história e, para viver, devem trabalhar e ter os meios que permitam a produção da própria vida material, condição fundamental de toda a história.

Baseando-se em Marx e Hegel, Marcuse reflete sobre o lugar do trabalho na existência humana como o modo de ser do homem como ser histórico, que, através de sua história, sua práxis, faz acontecer sua própria existência, por meio da produção e reprodução material e espiritual, que se dá num determinado tempo e lugar e, portanto, condicionada pela realidade social e econômica desenvolvida pelo processo histórico dos homens, objetivando a continuidade da vida humana, sua permanência e plenitude.

A distinção entre o reino da necessidade e o reino da liberdade é fundamental para a discussão desenvolvida a seguir e constitui o ponto central da reflexão, uma vez que o significado que o trabalho tem para homens e mulheres, numa dada organização social, estará comprometido com a racionalidade econômica que os direciona.

Marx divide o conceito geral de trabalho em dois planos. O primeiro é chamado de reino da necessidade: compreende o que é necessário para a sobrevivência dos homens e corresponde à produção e reprodução material. $\mathrm{O}$ segundo, chamado por Marx do reino da liberdade, é a práxis existencial que vai além da produção e reprodução material, expressando, ao mesmo tempo, a necessidade de integração desses dois planos.

"O reino da liberdade só começa, de fato, onde cessa o trabalho que é determinado pela necessidade e por objetivos externos; por conseqüência, em virtude da sua natureza, encontra-se fora da esfera da produção material propriamente dita (...) A liberdade neste campo só pode consistir no fato de a humanidade socializada, os produtores associados, regularem racionalmente o intercâmbio com a natureza, submetendo-a ao seu comum controle, em vez de serem governados por ela como por um poder cego, e cumprindo a sua tarefa com o menor dispêndio de energia possível e em condições tais que sejam próprias e dignas de seres humanos. (...) o desenvolvimento da poten- 
cialidade humana com fim em si mesma, o verdadeiro reino da liberdade que, no entanto, só pode florescer tendo como base o reino da necessidade. A redução do dia de trabalho é a sua condição prévia fundamental" (Marx, 1993:12).

O reino da liberdade acontece quando o homem está livre da necessidade imediata da existência, podendo se tornar livre para suas possibilidades, suas potencialidades. Além do urgente e das necessidades, há, também, práxis, trabalho a desenvolver; seu caráter se transforma.

Para Marx, a divisão da sociedade em classes e a apropriação dos meios de produção pela classe dominante reduzem o fazer acontecer da existência apenas para a dimensão da necessidade, para a maioria dos homens.

A separação da produção e reprodução, ou seja do reino da necessidade, ao reino da liberdade, que confere plenitude à existência, faz com que a dimensão econômica, ou a racionalidade econômica, absorva o todo existencial em seu interior e objetifica a práxis livre da existência.

A superação dessa divisão entre produção e reprodução do todo existencial, através da possibilidade de descobrir a plenitude do ser na existência dos homens, constitui a condição para que seja devolvida à existência seu trabalho próprio e para que o trabalho libertado da alienação e coisificação se torne novamente aquilo que é em sua essência: a realização efetiva, plena e livre do homem em seu mundo histórico (Marcuse, 1998:44).

A definição do trabalho abstrato também é fundamental como categoria de análise do estudo em questão. Em Hegel, o trabalho é considerado uma atividade universal, por sua própria natureza; por isso, o trabalhador torna-se universal e os produtos resultantes do trabalho são permutáveis entre todos os indivíduos. É este universal do trabalho que o torna abstrato é através do trabalho que o indivíduo satisfaz suas necessidades. O objeto do trabalho passa a ser universal, transformando-se em mercadoria. Assim, o trabalho torna-se o trabalho abstrato universal, o trabalho só tem valor como atividade universal: seu valor é determinado pelo que o trabalho representa para todos e não apenas para o indivíduo.

Este trabalho abstrato universal liga-se às necessidades concretas individuais pelas "relações de troca" do mercado. Em virtude da troca, os produtos do trabalho são distribuídos entre os indivíduos segundo o valor do trabalho abstrato. Marcuse acentua dois pontos: a subordinação do homem ao trabalho abstrato; e o caráter cego de uma sociedade perpetuada pelas relações de troca. "O tra- balho abstrato não pode desenvolver as verdadeiras faculdades do indivíduo" (Marcuse, 1969:81).

Ao contrário, o trabalho concreto é o caráter útil do trabalho, aquele que produz o valor de uso das mercadorias e cria coisas úteis e necessárias. A definição dos conceitos centrais do trabalho apontados anteriormente é a base para uma reflexão sobre o significado do trabalho para os homens em sua realidade concreta.

Na tentativa de apreensão do conceito de ontologia do ser social, procurou-se elucidar o caráter ontológico do trabalho, para se ter maior clareza do que acontece com o homem no ato produtivo.

\section{O Caráter Ontológico do Trabalho}

Procurando desvendar os fundamentos ontológicos do trabalho, serão citados autores cujas obras tratam do trabalho numa perspectiva ontológica do ser social. O entendimento do conceito de ontologia é fundamental para a reflexão sobre o significado do trabalho.

"A ontologia é termo de origem recente na filosofia, data do século XVII, (...) designando o estudo da questão mais geral da metafísica, a do 'ser enquanto ser', isto é, do ser considerado independente das suas determinações particulares e naquilo que constitui sua inteligibilidade própria” (Japiassu, 1993:184).

A fundamentação filosófica do conceito de trabalho se sustenta na dimensão ontológica do ser, possibilitando uma visão ampliada da existência humana e situando o trabalho além da esfera econômica.

Para Marcuse (1998:10), baseado em Hegel, o trabalho é um conceito ontológico que apreende o ser da própria existência social. Para Hegel, o caráter ontológico do trabalho aparece como acontecimento fundamental da existência humana, que domina permanente e continuamente todo o ser do homem e, concomitante a isso, algo acontece com o ser do homem, ele se transforma.

Antunes (1995:123), citando Luckács, aponta “o trabalho como momento fundante da realização do ser social, condição para sua existência; é o ponto de partida para a humanização do ser social e o motor decisivo do processo de humanização do homem". Através do trabalho ocorre uma dupla transformação: ele atua sobre a natureza, desenvolve as potências nela ocultas e o homem é transformado pelo trabalho. O trabalho permite, num processo dialético, o crescimento e o desenvolvimento da pessoa como um ser criativo, possibilitando tornar-se sujeito, na realização de sua potência, ao longo de uma vida. 
Porém, também na maioria das vezes, a realidade econômica da sociedade capitalista viabiliza situações de espoliações, alienação e sofrimento. Sobre este aspecto, Antunes (1995) cita Marx, para quem o trabalho é o elemento-chave da humanização do ser social, no entanto, na sociedade capitalista, ele é degradado, estranhado e, em vez de ser meio de realização de homens e mulheres, se transforma em meio de subsistência.

Antunes (1995:123), citando Luckács, afirma que o conceito de trabalho "na ontologia do ser social é uma categoria qualitativamente nova”. O ato teleológico é seu elemento constitutivo central. A consciência humana deixa de ser mera adaptação ao meio ambiente e torna-se uma atividade autogovernada. Em sua origem, o trabalho, ontologicamente, conduz o processo de humanização do homem em seu sentido amplo. Segundo Luckács, a transformação interior do homem consiste em atingir um controle sobre si mesmo.

A proposta de uma vida cheia de sentido está fundamentada, para Antunes, no caráter ontológico do trabalho, na possibilidade que ele tem em si, de favorecer ao homem, o seu desenvolvimento como ser criativo e desenvolver sua potência.

Este autor inicia a discussão sobre a busca de uma "vida cheia de sentido", situando tal questão na relação existente entre trabalho alienado e trabalho concreto, entre reino da necessidade e reino da liberdade e referindo a "vida cheia de sentido" ao trabalho concreto, ao reino da liberdade.

Antunes refere-se a uma vida cheia de sentido, que encontra, no plano do trabalho, seu primeiro momento de realização, afirmando, ao mesmo tempo, que uma vida cheia de sentido não acontece exclusivamente no traba1ho. A arte, a poesia, a pintura, a literatura, a música, o momento de criação e o tempo de liberdade têm um significado muito especial. São por esses meios que o ser social poderá se humanizar e emancipar em seu sentido mais profundo.

Para Luckács, o conteúdo da liberdade é essencialmente distinto nas formas mais avançadas. O ato teleológico, expresso por meio da colocação de finalidades, é, portanto, uma manifestação intrínseca de liberdade, no interior do processo de trabalho. É um momento efetivo de interação entre subjetividade e objetividade, causalidade e teleologia, necessidade e liberdade. O autor coloca ainda que, na interação entre o trabalho e as formas mais complexificadas da práxis social interativa, existe uma relação de prolongamento, de distanciamento e não de separação e disjunção porque: "Pelo trabalho o ser social produz-se a si mesmo como gênero humano; pelo processo de auto-atividade e autocontrole o ser social salta da sua origem natural baseada nos instintos para uma produção e reprodução de si como gênero humano, dotado de autocontrole consciente, caminho imprescindível para a realização da liberdade" (Antunes, 1999:145).

Refletindo sobre a crise do trabalho na sociedade atual, em que muitos autores colocam em discussão a questão da centralidade do trabalho, Antunes localiza a referida crise como a crise do trabalho abstrato, aquele que não pode desenvolver as várias faculdades do ser social. Entende o trabalho abstrato como dispêndio da força humana de trabalho, que cria o valor das mercadorias, e o trabalho concreto como dispêndio da força humana dirigida para um determinado fim e, nessa qualidade de trabalho útil e concreto, produz o valor de uso das mercadorias.

Assim, o trabalho concreto é o caráter útil do trabalho, o trabalho criado, que cria coisas realmente úteis e necessárias. O trabalho abstrato é o sentido genérico do trabalho, enquanto dispêndio da força produtiva, física ou intelectual, socialmente determinada, perdendo as formas de trabalho concreto, já citados, no que concerne ao sentido do trabalho e sua visão ontológica.

Mais uma vez, a discussão que se coloca, então, diz respeito à distinção entre o reino da necessidade e o reino da liberdade, entre trabalho abstrato e trabalho concreto. Assim, pergunta-se: existe o trabalho não alienado? A humanidade é capaz de produzir uma sociedade onde o trabalho é a realização do ser social? Na busca de caminhos, pode-se retornar a Antunes (1995:80), para quem "a superação da sociedade do trabalho abstrato se dá no reconhecimento do papel central do trabalho assalariado, da classe que vive do trabalho, como sujeito, potencialmente capaz de caminhar, objetiva e subjetivamente, além do capital".

"O salto para além do capital será aquele que incorpore as reivindicações presentes na cotidianidade do mundo do trabalho como a redução radical do tempo livre sob o capitalismo, desde que esteja articulada com o fim da sociedade do trabalho abstrato e sua conversão em uma sociedade produtora de coisas úteis, na construção de uma organização societária que caminhe para a realização do reino da liberdade, momento de identidade entre o indivíduo e o gênero humano" (Antunes, 1995:81).

O autor ressalta que o trabalho não é o único e totalizante momento da construção da vida do ser social, mas, através do trabalho concreto, se dará o ponto de partida, a base de sustentação para instauração de uma nova sociedade. 
A nova proposta societal de uma vida cheia de sentido baseia-se em dois princípios básicos para Antunes: primeiro, o atendimento às necessidades humanas societais, o que é considerado, pelo autor, o mais profundo desafio da humanidade, pois o capital instaurou um sistema de autovalorização que independe das reais necessidades autoreprodutivas da humanidade, as quais devem ser recuperadas; e segundo, a conversão do trabalho em atividade livre, auto-atividade com base no tempo disponível, significando a recusa à dicotomia existente entre tempo de trabalho necessário para a reprodução social e para a reprodução do capital.

"E esse mesmo trabalho autodeterminado que tornou sem sentido o capital gerará as condições sociais para o florescimento de uma subjetividade autêntica e emancipada, dando um novo sentido ao trabalho" (Antunes, 1999:182).

O autor compreende a classe trabalhadora de hoje como o "conjunto heterogêneo e complexificado do trabalho, incorporando tanto os segmentos minoritários e mais qualificados, como também os segmentos assalariados, os trabalhadores temporários, os terceirizados, os subcontratados, etc. que compõem a totalidade do trabalho social" (Antunes, 1999:183).

Dejours (1994:143) coloca que o trabalho aparece definitivamente como operador fundamental na própria construção do sujeito. O trabalho não é apenas "um teatro aberto ao investimento subjetivo", ele é também um espaço de construção do sentido, portanto, da conquista da identidade, continuidade e da historicização do sujeito.

Diante da realidade concreta dos trabalhadores em questão e da reflexão colocada por Ricardo Antunes sobre a possibilidade de uma "vida cheia de sentido" tanto dentro como fora do trabalho e a realização do trabalho concreto, útil, na realização do reino da liberdade para além da necessidade, pergunta-se: é possível, numa sociedade capitalista, o trabalho alienado ser um espaço de realização pessoal, de autotransformação do homem, do preenchimento do seu vazio, a expressão de seu ser no mundo?

A seguir, apresentam-se alguns pontos de reflexão a essas indagações, a partir da pesquisa desenvolvida junto aos trabalhadores.

\section{O Sentido do Trabalho na Experiência Concreta dos Trabalhadores}

Procurou-se situar a realidade concreta dos trabalhadores da indústria têxtil de amianto, objeto dessa pesquisa, e a partir desta realidade fazer a reflexão do sentido do trabalho.
Ao serem indagados sobre o significado do trabalho para suas vidas, os trabalhadores apontam como primeira motivação a necessidade econômica de sobrevivência. No entanto, é ressaltada a importância do trabalho: "O trabalho é tudo" (trabalhador da indústria têxtil de amianto).

A maioria dos trabalhadores - homens e mulheres gostava do seu trabalho. Pode-se observar o aspecto ontológico do trabalho, como auto-realização humana, na busca de uma vida com sentido. "Todo trabalho que a gente gosta é importante. Gostava do trabalho e do salário” (...) "Fazer o que se gosta preenche uma satisfação, conseguir realizar o que se gosta, preenche uma satisfação" (trabalhadores da indústria têxtil de amianto).

Para Simoni, o trabalho, no saber tradicional, é um meio de transcendência, não apenas a relação entre homem e natureza; mas a busca, a realização de cada pessoa com sua origem divina. $O$ trabalho passa então a suprir necessidades não só desse mundo, mas do mundo originário da espécie humana (Simoni, 1996:43).

O aspecto ontológico do trabalho e seu significado são expressos pelos trabalhadores através de suas falas. "Só saí porque me mandaram embora. Eu gostava do meu serviço. Eu fazia um serviço que era muito útil a certas áreas. Fazia sapata de freio de trem, gaxeta para navio, etc. Eu era mais empresa do que eu. Vê os bombeiros, tão importantes" (trabalhadora da indústria têxtil de amianto).

A interpretação da trabalhadora sobre sua atividade revela a importância que o trabalho adquire para ela, com repercussões úteis e positivas para outras pessoas. Tal proposição "transcende o sentido meramente instrumental da atividade produtiva," além de servir o outro no caminho de sua busca pessoal (Simoni, 1996:14-21).

"O trabalho é você ganhar o pão de cada dia, ocupar o seu espaço. Quando fico sem fazer nada não me sinto bem, trabalho desde os treze anos. Chego em casa e faço a obra da casa" (trabalhador da indústria têxtil de amianto).

Os trabalhadores se sentem muito importantes como pessoas e, principalmente, por ajudar a família. Muitos trabalhadores fazem referência ao trabalho apenas pelo aspecto econômico. Para outros, existe de forma acentuada uma preocupação com a autonomia econômica e a autonomia psíquica que influencia seu entendimento enquanto sujeitos atuan tes na construção de sua própria vida e da família.

"Quando comecei a trabalhar tinha o significado de sacrifício meu. Minha mãe não deixava a gente trabalhar só quem trabalhava era ela.(...) Ali tinha um significado. Era para ajudar as prestações da casa. Ali tinha prazer eu gostava!" (trabalhadora da indústria têxtil de amianto). 
As relações de amizade são vivenciadas como muito importantes no ambiente de trabalho e se apresentam como ampliação ao mundo do trabalhador. Simoni reconhece o local de trabalho como espaço a compartilhar com os companheiros, o que implica assumir o caráter pessoal e coletivo do trabalho. "Aí ocorrem as verdadeiras relações humanas perpassadas pela responsabilidade, respeito e solidariedade" (Simoni, 1996:24).

No que diz respeito às condições de saúde, após o conhecimento do diagnóstico, os depoimentos das trabalhadoras expressam decepção e tristeza.

"Se eu soubesse que trabalhando naquela firma ia acontecer o que aconteceu, se eu tivesse conhecimento eu não teria trabalhado lá não! (...) Não sabia que ia chegar ao ponto que cheguei. Podendo trabalhar mais doze anos, talvez até mais. Talvez até me aposentar por tempo de serviço. Não tive essa oportunidade" (trabalhadora da indústria têxtil de amianto).

$O$ fato de não poder trabalhar mais por problemas de saúde traz um sentimento de tristeza e de utilização como objeto. Junto à questão da saúde, a demissão é outro motivo de sofrimento.

A partir da experiência dos trabalhadores, constatamos que, mesmo em condições tão opressivas de trabalho, as pessoas encontram pequenos espaços para situar o sentido para o seu trabalho. No início da pesquisa, levou-se a hipótese de que, no trabalho estranhado e com alto nível de exploração, os trabalhadores dariam importância apenas à questão da sobrevivência. Entretanto, verificou-se, pela fala dos trabalhadores, que mesmo sob más condições de trabalho, que não excluem sofrimento, esforço e dor, existe a alegria da realização, da criação de um fazer humano e do sentimento de participação no mundo. No entanto, deve-se ressaltar que este é um espaço, apenas uma brecha encontrada na organização opressiva do trabalho, que demonstra a relevância do trabalho como esfera de criação, relação com os outros, reconhecimento e transcendência. Entretanto, estes fins que o trabalho contempla são negados como proposta coletiva para toda a sociedade. É esta finalidade que se sugere para todas as pessoas numa organização societária, diferente da que existe, que contemple uma "vida cheia de sentido" (D'Acri, 2002).

\section{CONCLUSÕES}

O estudo da indústria têxtil de amianto que diagnosticou diversos casos de asbestose traz uma contribuição significativa para a área de saúde, uma vez que trata-se de uma realidade desconhecida pelas autoridades sanitárias no Rio de Janeiro.

As relações e inter-relações entre diagnóstico, posto de trabalho, tempo de serviço, atividades desenvolvidas, exposição à poeira do amianto e a distribuição por sexo dos setores produtivos e dos diagnósticos de saúde foram variáveis que contribuíram de forma significativa para a efetivação da análise da realidade e da compreensão do objeto.

A fonte principal dessa pesquisa foi a realidade dos trabalhadores, através do diagnóstico de saúde e da vivência da condição opressiva de trabalho, direcionada por uma organização rígida, cujo ritmo e cadência das máquinas exigem um grande esforço e sofrimento dos trabalhadores, intensificando o trabalho relacionado com o diagnóstico médico elaborado pela equipe médica do Cesteh.

Quanto às condições de saúde, diante da morbidade e mortalidade dos trabalhadores atendidos no Cesteh, fica mais uma vez comprovada a nocividade do amianto. Pelos dados revelados por este estudo e pelas pesquisas desenvolvidas pela equipe de saúde, sobre os trabalhadores da indústria em questão, considera-se inaceitável a proposta do uso seguro do amianto crisotila, estudado por pesquisadores internacionais que revelam seus efeitos patológicos e cancerígenos. Portanto, não existe uso seguro do amianto e a recomendação deve ser de banimento total de toda e qualquer fibra de amianto.

A partir dos dados concretos referentes à saúde e às condições de trabalho, indagou-se sobre o sentido do trabalho para esses trabalhadores. A questão colocada na pesquisa está relacionada à importância que os trabalhadores dão ao seu trabalho não apenas como meio de vida, de sobrevivência, mas sobretudo como sentido para suas vidas. E como se dá, no desenvolvimento do trabalho alienado, abstrato e estranhado, o trabalho com significação, com sentido para os trabalhadores.

No que diz respeito ao significado do trabalho, os trabalhadores da indústria têxtil do amianto relatavam, durante as entrevistas, sua experiência com o real do trabalho; as formas como era solucionado o insucesso com as tarefas prescritas, a inovação e a criatividade para atender o real do trabalho e, principalmente, o sentimento agradável, ou não, do reconhecimento de seu trabalho pelas chefias e direção da empresa. Observaram-se o aspecto estruturante que o trabalho tem em suas vidas e, concomitantemente, a característica contraditória do fazer laborativo: más condições de trabalho - calor e ruído excessivo -; intensificação do trabalho; formas de controle 
pela gerência; risco à saúde dos trabalhadores; e conseqüente adoecimento.

Ao desenvolver o estudo, percebeu-se que mesmo o trabalho estranhado tem a marca do trabalhador: ele se coloca no trabalho, considera-o parte de sua vida, dá sentido a mesma. O trabalhador desenvolve o caráter ontológico do trabalho a partir dos fundamentos teleológicos de sua ação e, embora limitado pela organização do trabalho, ele tem um mínimo de liberdade. Quando este mínimo de liberdade não existe começam o sofrimento e a luta contra o ele.

Ao lado da efetivação da atividade de trabalho como uma "necessidade para satisfazer outras necessidades", como afirma Marx, o trabalhador busca sua realização e valorização pessoal, se sente útil.

Ricardo Antunes, na proposta de construção de uma nova sociedade, vê a realização da "vida cheia de sentido" tanto dentro quanto fora da esfera do trabalho, através de uma nova organização societária que responda às necessidades humanas, no lugar da valorização constante do capital, uma sociedade que dê o salto para além do capital, por meio da transformação do trabalho em atividade livre, e que, em contraposição ao trabalho fetichizado, estranhado e abstrato, se realize a sociedade do trabalho concreto, com a produção de coisas úteis, mudando o reino da necessidade, em que se encontram os trabalhadores, para o reino da liberdade.

Todos esses autores vêem o trabalho como realização, como fonte de criação para o homem. Proposta distinta de uma sociedade voltada para uma economia de mercado e de consumo que não hesita em prejudicar a vida de milhares de pessoas. Entretanto, a própria valorização que os trabalhadores dão ao seu trabalho e o sentido que encontram na sua vida de trabalho, mesmo em condições adversas, apontam para a superação desta realidade e a construção de um outro modo de sociedade e de uma "vida cheia de sentido."

Na experiência concreta dos trabalhadores, constatouse o valor atribuído por eles ao seu trabalho. Observou-se que, através do trabalho, os trabalhadores encontram espaços para realizar o seu modo de ser no mundo; encontram sentido para sua vida. O reconhecimento de sua atuação profissional é muito valorizada pelos trabalhadores.

Paralelamente, as relações de amizade e as afetivas são consideradas muito importantes em suas vidas de trabalho, ampliando seu mundo e colocando-os num universo coletivo. Ao mesmo tempo, o aspecto contraditório do trabalho é vivenciado de forma acentuada. O caráter opressivo - o sofrimento do trabalho - é uma das característi- cas mais marcantes na sociedade capitalista, no trabalho alienado. Dejours localiza na organização do trabalho a responsabilidade de todas as pressões sofridas pelos trabalhadores.

Tal sofrimento é relatado na velocidade da máquina, no ritmo intenso de trabalho, nas temperaturas elevadas, no excesso de ruído, nas condições precárias da matériaprima (o barbante que arrebenta, exigindo mais atenção, mais interrupção, num fazer laborativo que tem uma produtividade a ser alcançada, exigindo a intensificação dos gestos e movimentos) e também nas relações de gênero, em que as mulheres têm tratamento diferenciado.

O sofrimento é relatado também através da demissão. Muitos trabalhadores foram demitidos após muitos anos de serviço e dedicação à empresa. Sentem não terem sido levados em consideração e serem tratados como um número, um objeto, e não como pessoa. A lógica da demissão já está dada, no próprio momento da contratação. Assim que os trabalhadores começam a sentir os primeiros sinais de cansaço, indicando o início de problemas de saúde, são demitidos sem nenhuma informação sobre suas condições de saúde.

O cansaço do corpo, a opressão e o diagnóstico das doenças causadas pelo amianto, reduzindo sua capacidade respiratória, modificando suas vidas e, algumas vezes, incapacitando-os para o desenvolvimento de qualquer atividade laborativa, limitam a vida desses trabalhadores e trazem sofrimento pelo não reconhecimento do trabalho desenvolvido anos a fio na empresa e, mais recentemente, pelo conhecimento da patogenicidade do amianto e da morte de vários trabalhadores com diagnóstico de asbestose.

Portanto, coloca-se a pergunta: se, em condições tão adversas de trabalho, é possível encontrar um sentido para o trabalho, embora este sentido se dê em pequenas brechas, pode-se imaginar o quanto de possibilidade existe numa outra organização social voltada para o sentido da vida, do trabalho, das pessoas?

Assim, diante do que foi exposto, é bastante possível a proposta colocada por Ricardo Antunes de uma vida cheia de sentido, em outra organização societária com base no trabalho livre, concreto, em que a racionalidade não estará dirigida para o mercado, para o capital, mas sim para atender às necessidades humanas e à realização do trabalhador. Nestas condições, a atividade criativa será bastante ampliada, trazendo maior alegria para homens e mulheres; e o trabalho será um espaço fundamental de criação e realização. 


\section{REFERÊNCIAS BIBLIOGRÁFICAS}

ANTUNES, R. Os sentidos do trabalho: ensaio sobre a afirmação e a negação do trabalho. 1. ed. São Paulo: Boitempo Editoral, 1999.

ANTUNES, R. Adeus ao trabalho? Ensaios sobre as metamorfoses e a centralidade do mundo do trabalho. São Paulo: Cortez, 1995.

CASTRO, H. et al. Estudo das condições de saúde, trabalho e vida dos trabalhadores de uma indústria têxtil de amianto no Rio de Janeiro. Rio de Janeiro: ENSP/Fiocruz, 1999. Mimeografado.

CASTRO, H.; LEMLE, A. Doenças do aparelho respiratório relacionadas à exposição ao asbesto. In: VIEIRA, S.I. (Org.). Medicina básica do trabalho. Curitiba: Genesis, v. III, 1995.

CASTRO, H.; GOMES, V.R. Doenças do aparelho respiratório relacionadas à exposição ao asbesto. Revista Pulmão, Rio de Janeiro, jan.-mar. 1998

CASTRO, H.A. et al. Implantação de um sistema integrado de vigilância em saúde do trabalhador para áreas que utilizam o amianto no Brasil. Cesteh/ENSP, 2001. Mimeografado.

D'ACRI, V. O significado do trabalho: o estudo das condições de trabalho e saúde dos trabalhadores de uma indústria têxtil de amianto no Rio de Janeiro. 2002. Tese (Doutorado) - Coppe/UFRJ, Rio de Janeiro, 2002

DEJOURS, C.; ABDOUCHELI, E.; JAYET,C. Psicodinâmica do trabalho: contribuições da escola dejouriana à análise da relação prazer, sofrimento e trabalho. 1. ed. São Paulo: Atlas, 1994.

GIANNASI, F.; SCAVONE, L.; MONY, A.T. Doenças laborais provocadas pelo amianto e a construção de uma cidadania de pro- testo - uma abordagem interdisciplinar em saúde do trabalho, meio ambiente e gênero. Revista Cipa, v.235, n.20, p.54-57, 1999.

JAPIASSU, H.; MARCONDES, D. Dicionário Básico da Filosofia 2. ed. Rio de Janeiro: Jorge Zahar Editor, 1993.

MARCUSE, H. Sobre os fundamentos filosóficos do conceito de trabalho da ciência econômica. Cultura e Sociedade. Rio de Janeiro: Paz e Terra, v.2, p.7-50, 1998.

$$
\text { . Razão e revolução. Rio de Janeiro: Saga, } 1969 .
$$

MARX, K. Os manuscritos econômicos e filosóficos. Textos filosóficos. Lisboa, Edições 70, 1993.

. O capital. (Crítica da Economia Política). 5. ed. Rio de Janeiro: Civilização Brasileira, Livro primeiro, v.1, 1980.

MARX, K.; ENGELS, F. A ideologia alemã. 11. ed. São Paulo: Hucitec, 1999.

MENDES, R. Asbesto (amianto) e doença: revisão do conhecimento científico e fundamentação para uma urgente mudança da atual política brasileira sobre a questão. Cadernos de Saúde Pública, v.17, n.1, p.7-29, jan./fev. 2001.

SIMONI, M. de. Trabalhar é preciso-Reflexões sobre o conceito de trabalho humano e suas implicações para a engenharia de produção. 1996. Tese (Doutorado) - Coppe/UFRJ, Rio de Janeiro, 1996.

VANDAD'ACRI: Assistente social, pesquisadora da Escola Nacional de Saúde Pública, Fiocruz-RJ(vdacri@ensp.fiocruz.br). 